\title{
Increasing line rate by combining ETDM and OTDM in a semiconductor Mach-Zehnder modulator
}

Liu, Fenghai; Zheng, Xueyan; Pedersen, Rune Johan Skullerud; Jeppesen, Palle; Fraser, Jim; Bainbridge, John D.; Cox, Mike

\section{Published in:}

Proceedings of Optical Fiber Communication Conference and Exhibit, 2001

Link to article, DOI:

10.1109/OFC.2001.927884

Publication date:

2001

Document Version

Publisher's PDF, also known as Version of record

Link back to DTU Orbit

Citation $(A P A)$ :

Liu, F., Zheng, X., Pedersen, R. J. S., Jeppesen, P., Fraser, J., Bainbridge, J. D., \& Cox, M. (2001). Increasing line rate by combining ETDM and OTDM in a semiconductor Mach-Zehnder modulator. In Proceedings of Optical Fiber Communication Conference and Exhibit, 2001 (Vol. 1) https://doi.org/10.1109/OFC.2001.927884

\section{General rights}

Copyright and moral rights for the publications made accessible in the public portal are retained by the authors and/or other copyright owners and it is a condition of accessing publications that users recognise and abide by the legal requirements associated with these rights.

- Users may download and print one copy of any publication from the public portal for the purpose of private study or research.

- You may not further distribute the material or use it for any profit-making activity or commercial gain

- You may freely distribute the URL identifying the publication in the public portal 


\title{
Increasing line rate by combining ETDM and OTDM in a semiconductor Mach-Zehnder modulator
}

\author{
Fenghai Liu, Xueyan Zheng, Rune.J.S. Pedersen* and Palle Jeppesen \\ Research Center COM, Technical University of Denmark, Building 349, DK-2800 Lyngby, Denmark \\ Phone: +45-45253845, Fax; +45-45936581, Email: lf@com.dtu.dk \\ * Now with Tellabs Denmark A/S \\ Jim Fraser, John D. Bainbridge and Mike Cox \\ High Performance Optical Component Solutions, Nortel Networks, Brixham Road, Paignton, Devon TQ47BE, United Kingdom \\ Phone: +44-1803-662649, Fax: +44-1803-662917, Email: jimfrasr@nortelnetworks.com
}

\begin{abstract}
Line rate is doubled by combining ETDM and OTDM techniques in a semiconductor Mach-Zehnder modulator. $20 \mathrm{~Gb} / \mathrm{s}$ optical signal is successfully generated using a $10 \mathrm{GHz}$ commercial module to multiplex two $10 \mathrm{~Gb} / \mathrm{s}$ signals.
\end{abstract}

\section{Introduction:}

Both electrical time-division-multiplexing (ETDM) and optical time-division-multiplexing (OTDM) techniques are used to increase line rate in fiber transmission systems [1,2]. In ETDM, $N$ sets of low speed (bit-rate of $B$ ) data streams are combined into one set of high speed (bit-rate of $N \cdot B$ ) data stream in the electrical domain, then modulated on an optical carrier to generate a high speed optical signal. Both a high speed electrical multiplexer and a modulator with bandwidth of $N \cdot B$ are needed. In OTDM, $N$ sets of optical signals with bit-rate of $B$ are directly multiplexed into one set of high speed optical signal (bit-rate of $N \cdot B$ ). Each of the low bit-rate signals must be carried on an optical short pulse train with a pulse-width narrow enough to reduce the crosstalk between OTDM channels. Hence, short optical pulse sources are normally needed in OTDM.

In this paper, a dual-electrode semiconductor Mach-Zehnder modulator is used to combine two sets of 10Gb/s electrical return-to-zero (RZ) signals, to compress the pulses using electro-absorption and to modulate CW light, so that finally a $20 \mathrm{~Gb} / \mathrm{s}$ optical signal is obtained. Since the bandwidth of the MZ modulator is only $10 \mathrm{GHz}$ instead of $20 \mathrm{GHz}$ and no short optical pulse source is used, this method is different from both conventional ETDM and OTDM, and it opens a new way to increase the line rate.

\section{Principle and demonstration:}

A Mach-Zehnder modulator consists of two arms configured into an interferometer. The refractive index of each arm can be independently modulated by electrical signals. CW light launched into the interferometer is subjected to the phase difference between the two arms, hence becomes intensity modulated at the output. The MZ modulator can be used to multiplex two sets of electrical signals in the time domain, which is shown in Fig.1. As an example, the left arm is modulated by a set of $10 \mathrm{~Gb} / \mathrm{s} \mathrm{RZ}$ signal $V_{L}(t)$, and the right arm is modulated by another set of $10 \mathrm{~Gb} / \mathrm{s} \mathrm{RZ}$ signal $V_{R}(t)$ which is delayed by $50 \mathrm{ps}$ in comparison with the signal in the left arm. These two sets of $10 \mathrm{~Gb} / \mathrm{s}$ electrical signals modulate the $\mathrm{CW}$ light passing through the modulator, and this leads to an electrical field $E(t)$ of the optical signal at the output of the MZ modulator given by:

$$
\dot{E}(t)=A \cos \left(\pi \frac{V_{L}(t)-V_{R}(t)}{2 V_{\pi}}\right) \cos \left(\omega t+\pi \frac{V_{L}(t)+V_{R}(t)}{2 V_{\pi}}\right)
$$

Here $V_{\pi}$ is the electrical voltage inducing $\pi$ phase shift in the arm and $\omega$ is the angular frequency of the optical carrier. The first cosine function describes amplitude modulation and the second cosine function describes phase modulation. To verify the basic principle, a computer simulation is made. Two sets of RZ signals are generated using a PRBS generator with a pattern length of $2^{7}-1$ at $10 \mathrm{~Gb} / \mathrm{s}$, interleaved by $50 \mathrm{ps}$. Pulse-width of the signal is controlled by Bessel filters to $40 \mathrm{ps}$. The two signals are applied to the two arms of a MZ modulator. Eye-diagrams of the two modulation signals are shown in Fig. 2 (a) and (b) and the eye-diagram of the modulated optical signal is shown in Fig. 2(c). From Fig. 2(c), we can see that a $20 \mathrm{~Gb} / \mathrm{s}$ RZ optical signal is obtained. Although the pulse-width varies from 29 ps to 32 ps as shown in Fig. 2(c) by double traces, depending on neighboring bits, the maximum 
pulse-width is still less than that of the driving pulses, owing to the pulse compression from the cosine transfer characteristic of the $\mathrm{MZ}$ modulator. Hence, the MZ modulator here acts not only as modulator, but also as multiplexer.

Normally, multiplexing of two $10 \mathrm{~Gb} / \mathrm{s}$ electrical RZ signals with a pulse-width of $40 \mathrm{ps}$ in a MZ modulator requires a bandwidth above $20 \mathrm{GHz}$. In contrast, we utilize the electroabsorption effect in the arms of a semiconductor MZ modulator to compress the pulses, thereby relaxing the bandwidth requirement. A $20 \mathrm{~Gb} / \mathrm{s}$ optical signal is successfully obtained in a $10 \mathrm{GHz}$ semiconductor $\mathrm{MZ}$ modulator.

The experimental setup is shown in Fig.3. A compact commercially available $10 \mathrm{~Gb} / \mathrm{s}$ transmitter module is used in the experiment. The module features full integration of a semiconductor MZ modulator, an optical isolator and a wavelength stabilized DFB laser, shown in the dashed frame of Fig. 3. Two arms of the modulator can be independently biased and modulated at $10 \mathrm{~Gb} / \mathrm{s}$. Fig. 4 shows the frequency response of one arm with low bias, where a $3 \mathrm{~dB}$ bandwidth of $11 \mathrm{GHz}$ can be seen. A $10 \mathrm{~Gb} / \mathrm{s}$ electrical $\mathrm{RZ}$ signal is generated using an electrical gate and a $10 \mathrm{~Gb} / \mathrm{s} \mathrm{NRZ} \mathrm{source} \mathrm{with} \mathrm{a} \mathrm{pattern} \mathrm{length} \mathrm{of} 2^{31}-1$ and peak-to-peak voltage swing of 4.8 Volt [3]. An eyediagram is measured and shown in Fig. 5(a) where a FWHM pulse-width of $60 \mathrm{ps}$ can be seen. The RZ signal is split into two sets by an RF power splitter, and one set of the $10 \mathrm{~Gb} / \mathrm{s}$ electrical RZ signal is applied to the right arm through a variable attenuator. The attenuator is used to equalize the electrical signal powers in case modulation signals are applied to both arms of the MZ modulator, and it is also used to block the modulation signal in case only single arm modulation is needed. The other set of the $10 \mathrm{~Gb} / \mathrm{s} \mathrm{RZ}$ signal is applied to the left arm through a variable delay line which is used to de-correlate the two signals and create $50 \mathrm{ps}$ interleave.

Single arm modulation experiments are made by setting the attenuator in the right arm to a very high value. Firstly, we use the modulator in the non-absorption range by setting the left bias to -2.6 Volt and the right bias to 0 Volt. Fig. 5(b) shows an eye-diagram when only one arm is modulated by the $10 \mathrm{~Gb} / \mathrm{s} \mathrm{RZ}$ signal in that case we can get a $10 \mathrm{~Gb} / \mathrm{s}$ optical RZ signal with a pulse width of 50ps which is not narrow enough to insert another TDM channel. Secondly, the bias on both arms are changed to deep bias (left arm to $-6.0 \mathrm{~V}$ and right arm to $-7.0 \mathrm{~V}$ ), and then the $\mathrm{MZ}$ modulator is forced to work in the absorption range. Fig. 5(c) shows an eye-diagram when only one arm is modulated in the absorption range by using deep biases; a pulse-width of $35 \mathrm{ps}$ can be seen. The MZ modulator can be used to compress pulses based on the electroabsorption effect in the deep bias state.

When the attenuator is set to a small value to insure that both arms of the MZ modulator are modulated with equal power, the two sets of $10 \mathrm{~Gb} / \mathrm{s}$ signals are multiplexed by the $\mathrm{MZ}$ modulator. At the same time, when both arms of the $\mathrm{MZ}$ modulator are deeply biased, the $\mathrm{RZ}$ pulses will become compressed due to electro-absorption effect in the two arms. This results in a $20 \mathrm{~Gb} / \mathrm{s}$ optical signal at the output. Eye-diagram of the $20 \mathrm{~Gb} / \mathrm{s}$ optical signal is shown in Fig. 5(d).

Since two sets of electrical signals are directly multiplexed by the semiconductor MZ modulator, and electroabsorption effect in the modulator is used to compress the optical pulses at the same time, we name this method Optical and Electrical Time Division Multiplexing (OETDM).

\section{Conclusion:}

A semiconductor $\mathrm{MZ}$ modulator is proposed to simultaneously multiplex two electrical $\mathrm{RZ}$ channels, compress the pulses and modulate optical light. A $20 \mathrm{~Gb} / \mathrm{s}$ optical signal is obtained using a $10 \mathrm{GHz}$ modulator. This method opens a new way to increase bit-rate per wavelength.

\section{Reference:}

[1] P. M. Krummrich, E. Gottwald, A. Schöpflin, C.-J. Weiske, K. Kotten and G. Fischer: “40 Gb/s ETDM for long haul WDM transmission", ECOC'2000, Vol.4, pp.13-14.

[2] B. Mikkelsen, G. Raybon and R.-J. Essiambre: "160 Gb/s TDM transmission systems", ECOC'2000, Vol.2, pp125-128.

[3] F. Liu, X. Zheng, C. Peucheret, S. N. Knudsen, R. J. S. Pedersen and P. Jeppesen: "Chirped return-to-zero source used in $8 \times 10 \mathrm{Gbit} / \mathrm{s}$ transmission over $2000 \mathrm{~km}$ of standard single mode fibre", Electronics Letters, 2000, vol. 36 , no. 12 , pp. 1399-1400. 


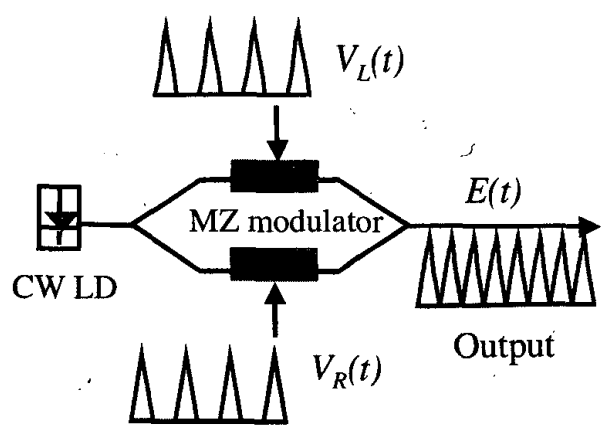

Fig. 1. Schematic diagram of ETDM transmitter using a $M Z$ modulator.

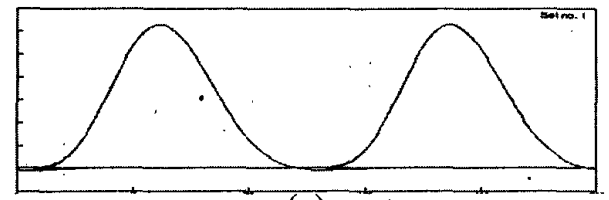

(a)

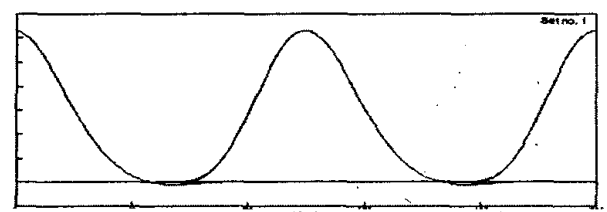

(b)

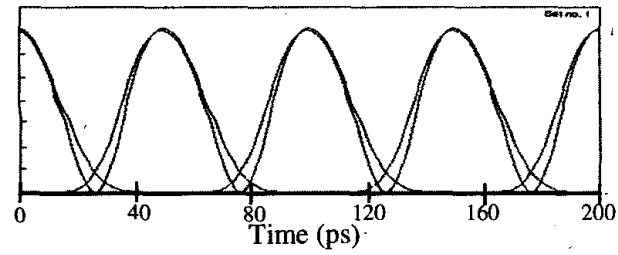

(c)

Fig. 2. Simulated eye-diagrams of the $10 \mathrm{~Gb} / \mathrm{s}$ modulation signal in left arm (a), right arm (b) and the modulated optical signal at the output (c).

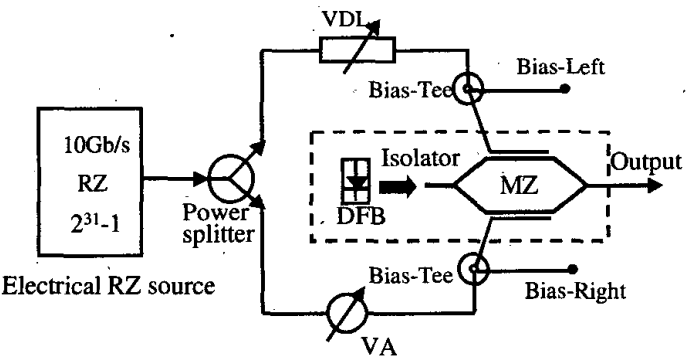

Fig. 3. Experimental setup of the $20 \mathrm{~Gb} / \mathrm{s}$ transmitter. VDL: variable delay line; VA: variable attenuator; MZ: semiconductor MZ modulator.

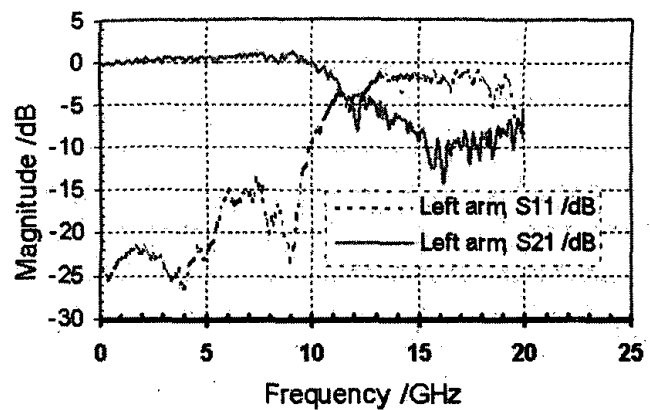

Fig. 4. Frequency response of the semiconductor MZ modulator.

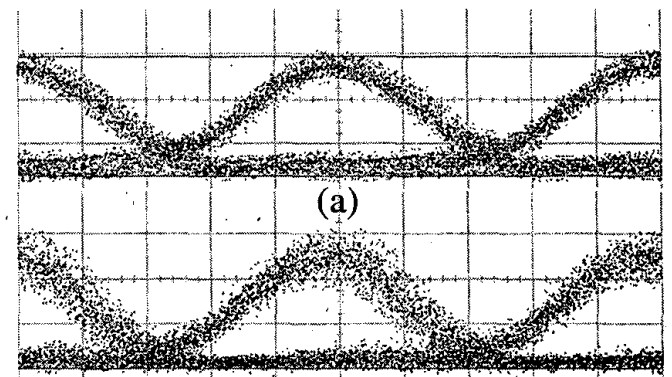

(b)

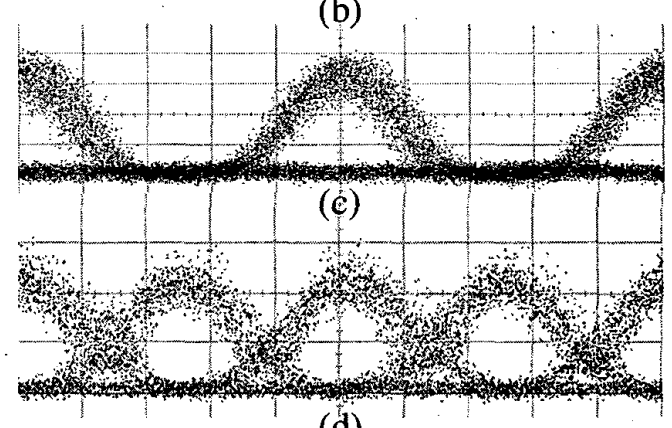

(d)

Fig. 5. Measured eye-diagrams of input electrical signal and output optical signal under different conditions, time scale: 20 ps/div. (a) input electrical signal. (b) output optical signal under single arm modulation in non-absorption range. (c) output optical signal under single arm modulation in absorption range. (d) output optical signal under dual arm modulation in absorption range. 